\title{
Cardiology Fellowship Training One Year into COVID 19 Pandemic: The Philippine General Hospital Experience
}

\author{
Lauren Kay M. Evangelista, MD, ${ }^{1}$ Marie Kirk Patrich A. Maramara, MD, ${ }^{1}$ Ruth Divine Agustin, MD, Jose Donato A. Magno, \\ $M D,{ }^{1}$ Felix Eduardo R. Punzalan, $M D^{1}$ \\ Division of Cardiovascular Medicine, Department of Medicine, University of the Philippines- Philippine General Hospital
}

Main Author: Lauren Kay M. Evangelista, MD

Email: Imevangelista2@up.edu.ph

\begin{abstract}
The previous year, 2020, was one challenging year for everyone, most especially to the healthcare workers. We experienced a pandemic no one ever imagined that would happen in our lifetime. Medical frontliners, the People Giving Hope, were called and were given the responsibility of taking care and defending the patients from the unfamiliar enemy, the COVID 19 virus. With the changes brought about the pandemic, transformation of the cardiology fellowship training also happened. Three Cardiology fellows in training gives us a sneak peek of how the pandemic affected their lives after a year of battling the virus.
\end{abstract}

\section{KEYWORDS}

Covid 19, Cardiology, Training

\section{INTRODUCTION}

March 15, 2020 - the National Capital Region of the Philippines was placed under community lockdown amidst the rapid surge of the COVID19 pandemic ${ }^{1}$ While most businesses, establishments and enterprises started folding up or closing down, the healthcare profession saw itself bracing for the impact of a yet unseen and uncharted battle. Meanwhile, the Division of Cardiovascular Medicine of the National University Hospital, like many other training programs in Cardiology, was still getting revved up for a fresh training year, as eager applicants had just hurdled their pre-fellowship phase, junior fellows were anticipating promotion, and the senior batch was excitedly looking forward to the muchcoveted graduation. It was only a matter of time before we all knew that our well-oiled plans and neatly-carved paths would make a drastic turn for uncertainty. The intimidating gloom cast by the COVID19 virus over the global community was felt more profoundly at the Philippine General Hospital, as its 4,000 workforce got wind of the news that their home-base was tagged by the Department of Health as a main COVID-referral center. ${ }^{2}$ Not a few raised stern objections or even violent reactions to the bold decision gracefully accepted by its brave medical director, as the faculty, fellows, residents, students, and paramedical staff frantically tried to make sense of the pandemic that was quickly taking over their loves and their lives. As Cardiology fellows-in-training, with zero experience in handling pandemics, a lot of questions filled our minds. Will this greatly affect our training as future cardiologists? How will the pandemic affect the practice of Cardiology? How will this revolutionize the Division of Cardiovascular Medicine?

Three cardiology fellows-in-training generously give us a sneakpeek into their life at the Philippine General Hospital, and how the pandemic has punctured some unusual portals of entry not only into their physical lives but through their souls and spirits.

\begin{abstract}
A Day in the Life of Cardiology fellow (PRE-CovID)
The most accurate word to describe the PGH Cardiology fellow's daily life is perhaps "hectic". Beginning with the receipt of endorsement from the post-duty fellow, our day proceeds with doing rounds on patients in the wards and the intensive care units. Our daily interaction with our patients is critical, not just for the training of our clinical senses but also for the monitoring of the dynamic states of our patients. One of the things Cardiology fellows are best known for is the ability to take a concise history and perform directed physical assessment on the patient. Perhaps among the medical specialties, Cardiology is one of the most reliant on the basic physical examination - inspection, percussion, palpation and auscultation. We are taught by our mentors that the first contact with the patient is of utmost essence - because it allows us to generate a clear-cut working impression and differential diagnoses, which guide our diagnostic and therapeutic management.
\end{abstract}

In between the daily grind of doing rounds are emergent referrals from different areas of the hospital, mostly involving acute chest pain, dyspnea, shock, and arrhythmias. Because these referrals entail making decisions that can make a difference between life and death, a Cardiology fellow's day is usually adrenalinecharged. At times, there is no time to pause or take a break, and physical needs are set aside.

Clinical work also involves our outpatient services. Catering to hundreds of patients per month, our Cardiology outpatient clinic is filled with throngs of Filipino indigent patients during clinic days, with a significant number coming from the provinces. As a government hospital offering advanced cardiovascular care, most of our patients come to PGH despite long travel times in order to avoid the expenses incurred in similarly equipped private hospitals.

Our conferences are held almost daily and remain integral in our training in Cardiology. Aside from serving as important venues for case-based learning and honing our presentation skills, conferences also allow our consultant mentors to help us review current evidence and share their experiences and insights about difficult cases. After conferences, socialization and personal interactions occur and allow us to form bonds, not only as colleagues but also as a family.

On a regular day, we usually finish our work beyond the 
designated office hours and remain in the hospital to finish whatever backlogs we have, including ECG and echo readings, and ensure that the succeeding day will flow smoothly. As such, a Cardiology fellow's Precovid life was akin to a glass that overflows with service, training and research, and our purpose was to make sure no drop was wasted so that we can become excellent Cardiologists for the Filipino people.

\section{New normal CVS fellow routine}

When PGH became a COVID -19 referral center, our daily routine was radically modified. A scheme to divide the whole section into teams was then implemented to ensure that our services and manpower our streamlined for our role as a Covid-19 Referral Center. Admissions of non-Covid cases were limited to life and limb threatening conditions and our outpatient services were put on hold. With change comes adaptation, but this was a challenge no one has experienced.

Whereas our precovid lives revolved around the intricacies of Cardiovascular Medicine, we were suddenly thrust into duties beyond our subspecialty. We were assigned to be part of the General Medicine pool of doctors who go on duty at COVID wards and ICUs, performing roles not as Cardiology Fellows but as Internal Medicine doctors.

Going on duty as internists in ICUs and wards entails mental, emotional and physical fortitude. While a novel experience, wearing level 4 personal protective equipment (PPE), with very hot and restrictive bunny suits, N95, goggles and face shields that tend to fog, was physically difficult, especially when wearing it for 8 hours straight. Mentally and emotionally, it was taxing as well. While the risk of contracting the disease with appropriate PPE is low, we could not fully eliminate our worries about becoming infected. One consequence of wearing PPE - human contact became very limited. Whereas smiles, handshakes, and pats on the back were the norm of the patient-physician interaction before, these simple non-verbal gestures were eliminated in our interactions with our patients admitted in the Covid zones. Our "holy grail" of history taking and physical examination became limited to inspection and brief palpation, as our PPEs now limit our ability to perform traditional auscultation. Whether in Covid or non-Covid areas, our daily rounds now consist of wearing a PPE, brief patient interactions and strict social distancing. With limited findings in physical examination, other parameters such as cardiac monitoring, echocardiography, and biomarkers have come to the fore as first-line tools in performing our subspecialty functions.

Training innovations were made by our consultant mentors to ensure that there was continuity of learning despite the limited number of cardiac cases being admitted in PGH. Online conferences became essential alternatives as we aimed to minimize gatherings. The cardiovascular manifestations of Covid-19, and the unique dilemmas we have to deal with in our subspecialty became central to our conferences.

\section{How are our patients now?}

Of all the changes that happened, the one with the most significant impact is perhaps the temporary closure of our Outpatient Department. Being a tertiary referral hospital, we see patients coming from nearby and far-flung areas most of them are elderly with comorbidities, classified among the vulnerable population. After several months of OPD closure, thanks to technology we were able to do telemedicine consults. And now we are slowly bringing back face to face consults, formulating ways on how we can safely do this. We have lost a number of our chronic patients in this battle. Some of them died at home while some passed away in other institutions that are not fully equipped in managing subspecialized cases. We have also noted a decrease in patients consulting at the emergency room especially on cases of Acute Coronary Syndrome during the early part of the pandemic, but for the previous months we have seen that patients starts coming in again, sensing that they now have less fear of going to the hospital.

\section{Accepting the challenge}

Never have we imagined that a Pandemic of this magnitude would reach us and become one of the ordeals we must surmount during our training as Cardiology fellows. Covid-19 has placed entire health systems, economies, and governments to a standstill and is continuously threatening not just our wellbeing but that of patients, our loved ones, and our comrades. The combination of personal and professional losses due to this Covid-19 Pandemic and the unspoken fears and anxieties constantly strain the core of our beings, even as we serve daily as frontliners. Being isolated from our beloved families was the toughest of all the challenges that we encountered. But we soldier on, for we have been called to serve during this battle.

\section{Embracing the new normal}

One year into the pandemic, we continue to engage in the battle against Covid-19, we recognize that there are still so many uncertain things in the future. Will the vaccine reach us? If yes, when? We have adapted to many changes on how to conduct outpatient clinics, shifted to Electronic medical records and charting and we are getting the hang of doing Telemedicine.

The new normal is not the usual that we have previously been inclined to do but the new normal brings us hope that we will be able to overcome Covid-19.

As we all move forward to our "new normal", may we always remember the mentors and comrades we have lost to the pandemic, that we honor their memories with the resolve to live on and live with their legacies. May we grasp the lessons of these challenging times and grow with them, not just as Cardiology fellows but also as integral threads in the web of humanity.

We are not sure about how long will this last, but we believe that this will end as long as we are together, and that our service and training during this Pandemic will make us better Cardiologists who will continue to hope, serve and impart a ray of light to fellow human beings in these dark times.

\section{REFERENCES}

1. Yap K and Jiao C. Manila Enters Lockdown for Month; Duterte Mulls Curfew [Internet] 2020 March 15 Available from :https://www.bloomberg. com/news/articles/2020-03-15/manila-enters-lockdown- for-month-dutertemulls-curfew-on-virus

2. Llaneta C. UP-PGH preparing to operate as COVID-19 referral center [Internet] 2020 March 24 Available from: https://www.up.edu.ph/up-pghpreparing-to-operate-as-covid-19-referral-center/ 